\title{
Spatial distribution of snares in Ruma National Park, Kenya, with implications for management of the roan antelope Hippotragus equinus langheldi and other wildlife
}

\author{
Johnstone K. Kimanzi, Roy A. Sanderson \\ Stephen P. Rushton and Mhare J. Mugo
}

\begin{abstract}
Poaching with snares has been identified as the main cause of decline of the endemic roan antelope Hippotragus equinus langheldi in Ruma National Park, Kenya, from $>200$ in 1979 to 37 in 2009. However, the spatial snaring patterns in the Park are not clearly understood. The focus of our study was to map the spatial distribution of snares in the Park and to identify the factors influencing this distribution, to develop effective methods of wildlife protection. Using data collected from 56 sample plots during 2006-2008, coupled with geographical information system techniques, we investigated the association between the occurrence of snares and the distribution of geographical features (slope, elevation), infrastructure (roads, fences), essential resources for wildlife (water, salt licks, forage), roan locations and wildlife density. Ripley's $L$ function for assessing complete spatial randomness indicated that snares occurred in clumps (hotspots) up to $4 \mathrm{~km}$ apart. Negative binomial regression indicated that these hotspots occurred (1) near water resources, salt licks and the Park boundary, (2) far from roan locations and Park roads, (3) in areas with low gradients and low wildlife density, and (4) in areas with burned vegetation. We recommend concentrating routine security patrol efforts and resources on snare hotspots to reduce snaring and to protect the roan antelope and other threatened wildlife.
\end{abstract}

Keywords Bushmeat, GIS, Hippotragus equinus langheldi, Kenya, roan antelope, Ruma National Park, snare distribution, spatial modelling

\section{Introduction}

$\mathrm{H}$ unting and associated forms of consumptive utilization of wildlife were banned in Kenya in 1977 because

Johnstone K. Kimanzi (Corresponding author) Department of Wildlife Management, University of Eldoret, P.O. Box 1125-30100, Eldoret, Kenya E-mail kimanzijo@yahoo.com

Roy A. SANDERson and StePHEN P. Rushton School of Biology, University of Newcastle, Newcastle upon Tyne, UK

Mware J. Mugo School of Natural Resources and Environmental Studies, Karatina University College, Karatina, Kenya

Received 1 November 2012. Revision requested 28 January 2013.

Accepted 5 April 2013. First published online 12 May 2014. they were seen as potential threats to many wildlife species (KWS, 1990). Consumptive utilization typically refers to the taking of wildlife for food, skins, ivory and other products (Barnett, 1997). Kenya has since maintained a restrictive stance, with policy focused on the promotion of non-consumptive forms of utilization, such as photography tourism (Ottichilo, 1995). Although poaching was significantly reduced initially, it was later exacerbated by the commercial demand for wildlife products and by people's resentment over restrictions on resource use (Carter, 1989). Kenya lacked the policy framework to ensure that benefits from non-consumptive utilization of wildlife reached the local people living adjacent to protected areas (KWS, 1990) and poaching is still rampant in these areas, except where community-based conservancies (e.g. Kimana, Mwalunganje and II Ngwesi) have been established (African Pro-poor Tourism Development Centre, 2013).

Bushmeat hunting has taken place in Ruma National Park, Kenya, since the Park was established in 1966 (Allsopp, 1979; Waweru et al., 1995). Population viability analysis of the roan antelope Hippotragus equinus langheldi in the Park (Kimanzi, 2012) identified poaching as the main cause of the decline from 200 in 1979 to 37 in 2009. Poaching using wire snares has been observed and documented by the Park authorities over the last 30 years (Kones, 2005; Kimanzi, 2012). Other methods of poaching, such as using dogs and bows and arrows, were used in the 1970s (Allsopp, 1979) but are no longer practised. The aim of our study is to provide a better understanding of the snaring patterns to inform the development of effective methods of wildlife protection. Our specific objectives are to (1) map the spatial distribution of snares in Ruma National Park, (2) identify the factors influencing the distribution of snares in the Park and (3) recommend methods of mitigating the effects of snaring in the Park, to promote recovery of the roan population and other threatened antelopes.

\section{Study area}

Ruma National Park lies in western Kenya (Fig. 1), in a valley between the Gwasi Hills to the west, the Kanyamwa Escarpment to the east and the Gembe and Ruri Hills to the north. The $120 \mathrm{~km}^{2}$ Park lies at an altitude of $1,170-1,750 \mathrm{~m}$. The vegetation in the Park is dominated by 


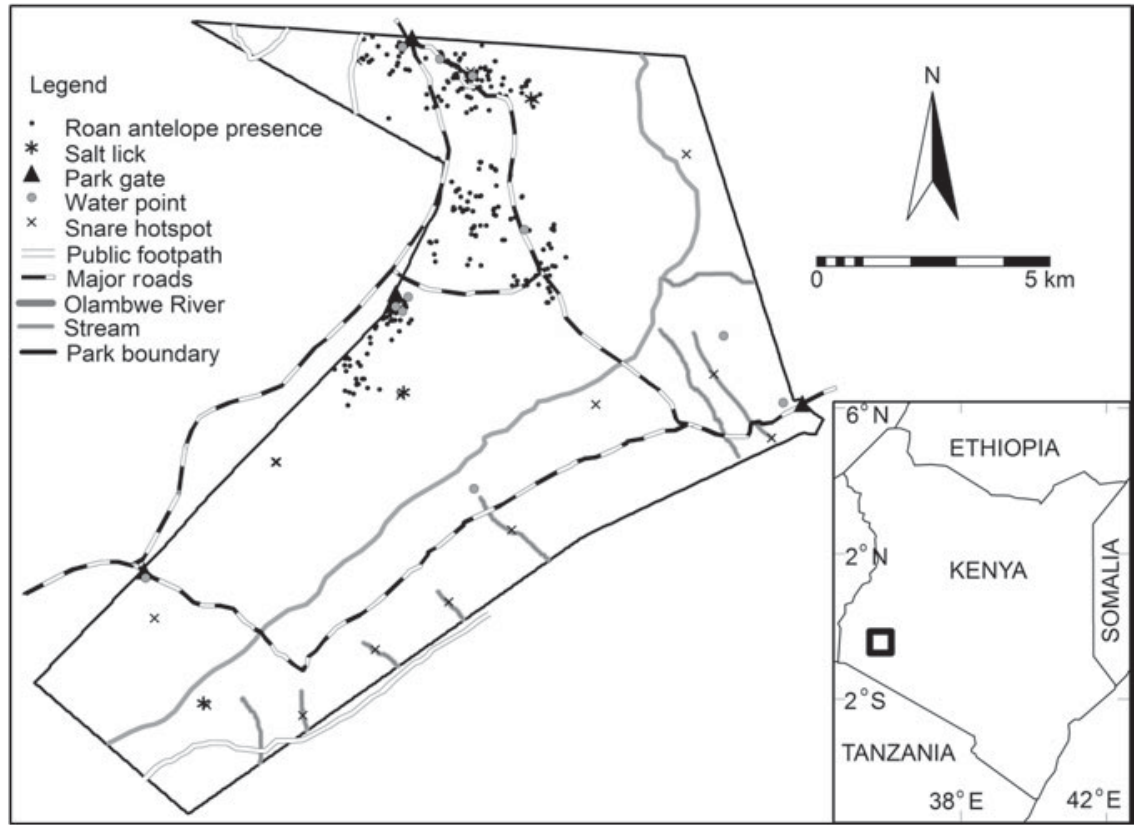

FIg. 1 The distribution of roan antelope Hippotragus equinus langheldi (indicated by black dots) in Ruma National Park. The rectangle on the inset shows the location of the Park in Kenya. savannah grassland and woodland, with extensive acacia thickets and bushes (Waweru et al., 1995). The mean annual temperature and rainfall are $28-30^{\circ} \mathrm{C}$ and $1,200-1,400 \mathrm{~mm}$, respectively (Omoto, 1994). The long rainy season typically occurs during March-June, and there is a shorter rainy season during September-November.

The Park was initially established as the Lambwe Valley Game Reserve in 1966 and was designated a National Park in 1983 (KWS, 1990), mainly to protect the threatened endemic roan antelopes, which are not found anywhere else in Kenya (KWS, 2006). Ansell (1971) described six subspecies of $H$. equinus ( $H$. equinus koba, $H$. equinus bakeri, $H$. equinus charicus, $H$. equinus equinus, $H$. equinus cottoni, and $H$. equinus langheldi) but the validity of most of these is unconfirmed and genetic studies have shown that only the West African subspecies ( $H$. equinus koba) is genetically distinct from roans in the rest of Africa (Alpers et al., 2004). The exact range of the East African subspecies (H. equinus langheldi) is still unknown. Although roans are categorized as Least Concern on the IUCN Red List (IUCN, 2008), if current trends continue, the roan's status may eventually decline as it disappears from large parts of its range as a result of poaching and loss of habitat.

\section{Methods}

\section{Data collection}

Park rangers collected data on snares while on routine patrols during 2006-2008. The patrol routes were designed to cover all areas of the Park and they followed all existing roads and firebreak tracks. The Park was divided into 10 blocks, similar to animal census blocks (Kimanzi, 2011), and each patrol route covered one block. The patrol design ensured that all blocks were visited five times per year for 3 years, amounting to 150 patrols. Patrols were carried out once per week throughout the year but for a total of 4 months during the 3 -year study period they were carried out once every fortnight as a result of vehicle breakdown or lack of fuel. To ensure that all parts of the Park were covered, vehicle patrols were combined with foot patrols to reach areas that were inaccessible to vehicles. Four rangers were transported by vehicle to an area within the target block, which they subsequently searched on foot. During the 3 years 651 snares were recorded in 56 locations. Each patrol covered a circular plot with a radius of c. $150 \mathrm{~m}$. There were 1-74 snares recorded per location. All snares were small (with a wire diameter $<5 \mathrm{~mm}$ ), suggesting that they were targeted at small- to medium-sized animals such as antelopes.

\section{Potential variables}

We considered 11 variables in our analysis of factors influencing the distribution of snares: wildlife density, slope, elevation, vegetation type, vegetation burned status, and distances from roan locations, water points, salt licks, security gates, the Park boundary and roads.

Studies have shown that hunters target different species depending on their main reason for hunting (subsistence or commercial), animal body size and species' abundance (Noss, 1998; Fa et al., 2005). Snare hunting tends to overexploit the most common species (Noss, 1998), and therefore the density of snares is predicted to be high in areas with a high density of targeted species. As most herbivores prefer habitats of low to moderate slope and 
elevation (Kimanzi, 2011) hunters may lay more snares in such areas. Hunters may also use their indigenous knowledge about suitable habitats for targeted species when placing snares (Gadgil et al., 1993). For example, many snares may be set in burned vegetation to target grazers attracted by the fresh grass that sprouts after fires. There may also be a higher density of snares in grasslands than non-grasslands if poachers are targeting grazers. Water and salt licks are essential resources for many wildlife species, and therefore setting snares in areas close to these resources could be rewarding for hunters. To avoid being caught, hunters may lay snares away from gates and outposts and relatively near the edge of the Park so that they can escape if they encounter rangers on patrol. Knowing how snaring patterns correlate with the road network in the Park can help rangers to ascertain whether vehicle patrols are deployed effectively or whether they need to be combined with foot patrols (Arcese et al., 1995).

We mapped each variable in a geographical information system (GIS) at a spatial resolution of $30 \mathrm{~m}$. Vegetation and slope maps were prepared by Kimanzi (2011) using a 2005 Landsat 7 ETM+ image and a digital elevation model, respectively. We included vegetation type and burned status as categorical variables in models; the other variables were continuous. The vegetation map layer was classified into grasslands and non-grasslands. Vegetation burned status was included as a single factor with two levels: burned and unburned. To compute the wildlife density we divided the mean wildlife estimates for 3 years (2006-2008) for each of the 10 animal counting blocks by the corresponding area. We derived all other distance maps from Ruma National Park boundary and infrastructure maps, using ILWIS (ILWIS, 2009).

\section{Variable selection}

To avoid the risk of including collinear explanatory variables we calculated the variance inflation factor for each variable: one explanatory variable is selected as the response variable and all the others are set as explanatory variables within a linear regression (Montgomery \& Peck, 1992). We calculated the variance inflation factor as $\mathrm{VIF}=1 /\left(1-R^{2}\right)$, obtaining $R^{2}$ from a linear regression. We performed a series of regression analyses, using a different explanatory variable as the response variable in each regression, and calculated the variance inflation factor for every explanatory variable. A high variance inflation factor indicates collinearity because it means that the variation in the response variable is accounted for by the other variables (Zuur et al., 2007, 2010). However, all variance inflation factor values were $<10$, which implied that there were no highly correlated explanatory variables. As there is no standardized cut-off value this decision is partly subjective. Some statisticians suggest that values $>10$ are too high (Montgomery \& Peck, 1992).

\section{Data analysis}

We carried out data analysis in $R$ v. 2.9.o (R Development Core Team, 2010). We used Ripley's $K$ and $L$ functions for spatial point pattern analysis to describe the distribution of snares in the Park, and the negative binomial regression to analyse the probability of snare occurrence.

Ripley's $\mathrm{K}$ and $\mathrm{L}$ functions Ripley's $\mathrm{K}$ function quantifies the spatial pattern intensity of points for a circular search window (Ripley, 1976). Points correspond to the locations of discrete events, in this case snares. The function computes the mean number of points lying within a circular search window of radius $t$ (Ripley, 1976): $\hat{K}(t)=\frac{\lambda^{-1} \sum_{i=1}^{n} \sum_{j=1}^{n} I_{t}\left(e_{i} e_{j}\right) / W_{i j}}{n}$ for $i \neq j$ and $t>0$, where the point intensity, $\lambda$, is estimated as the number of snares per unit area $(\mathrm{n} / A), I_{t}$ is an indicator function that has a value of 1 when $e_{j}$ is within distance $t$ of snare $e_{i}$ (and o otherwise), $\mathrm{n}$ is the total number of snares and $A$ is the area of the study plot. $W_{i j}$ is a fraction of the area, used to correct for edge effects. By using a circular window the function provided an isotropic cumulative count of all points at distances of $0-t$. The expected number of snares under complete spatial randomness is $\pi t^{2}$, the area of the search region.

To linearize and stabilize the variances the $\hat{K}(t)$ function was modified to the $\hat{L}(t)$ function (Venables \& Ripley, 2002), with $\hat{L}(t)$ calculated using the formula $\hat{L}(t)=\sqrt{\hat{K}(t) / \pi}$. We used Monte Carlo simulations of the Poisson point pattern process (i.e. complete spatial randomness) to provide a confidence envelope for the $L(t)$ function (Venables \& Ripley, 2002). For complete spatial randomness the plot of $L(t)$ against distance lies within the confidence envelope; plots above the envelope indicate an aggregated snare pattern and plots below the envelope indicate a regular pattern of snares. We used a Poisson cluster process to test for significance of the spatial clustering, using the Matern cluster process (Baddeley \& Turner, 2005).

Negative binomial regression The probability of snare occurrence in the Park, determined using negative binomial regression as an initial generalized linear model with a Poisson error distribution, indicated that overdispersion was a problem (Crawley, 2007). We investigated the significance of year of snare collection and clumped distribution of snares as random effect factors, using a generalized linear mixed model with a penalized quasi-likelihood (glmmPQL; Bolker et al., 2009). However, these two random effects had no significant effect on snare occurrence. We therefore used the negative binomial regression to complete our analysis of the probability of snare occurrence 


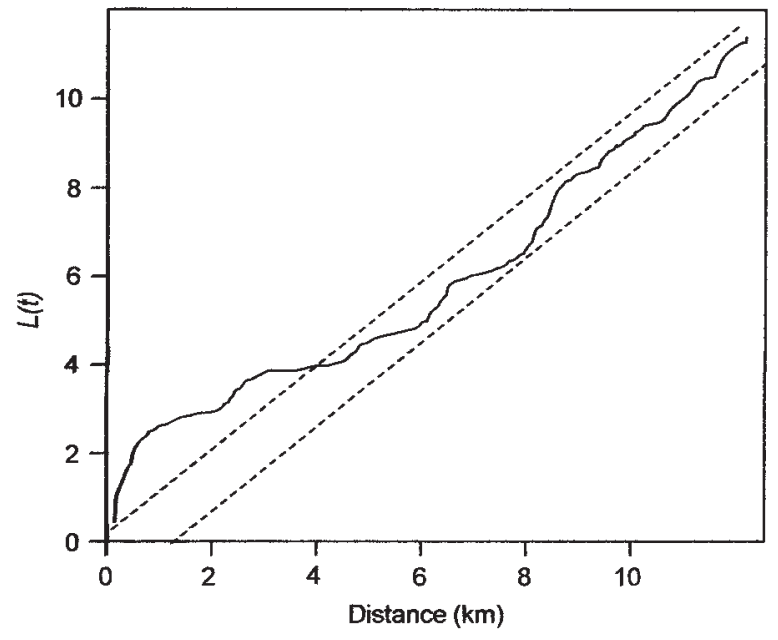

FIG. 2 Ripley's $L$ function for assessing complete spatial randomness of snares in Ruma National Park (Fig. 1). The dotted lines define a 95\% confidence envelope such that plots within the confidence envelope cannot be differentiated from complete spatial randomness, plots above the envelope are aggregated and plots below the envelope have a regular pattern.

in the Park. This method has been shown to yield good results with overdispersed data (Crawley, 2007).

Model assessment We used a bootstrapping technique (Manly, 2007) to validate the results of the negative binomial regression model. The technique was performed by resampling (with replacement) the snare data to construct bootstrap samples, leaving out 20 of the 56 data values at a time. We ran the bootstrap model 999 times and used its coefficients to assess the variability and bias in the coefficients of the original model.

\section{Results}

Analysis using Ripley's $L$ function showed that the snares in Ruma National Park have an aggregated pattern, occurring in clumps at distances up to $4 \mathrm{~km}$ (Fig. 2). A Poisson cluster process showed significant spatial clustering, as indicated by a $\kappa$ value of $5.91 \times 10^{-8}$ and a mean cluster size of 3.84 snares per point. The distribution of these snare clumps (hereafter referred to as snare hotspots) seems to be related to the distribution of several Park features, with many occurring near water points, salt licks and the Park boundary (Fig. 1).

We did not analyse the snare hotspots as independent points because of their limited number $(n=15)$. Instead we modelled snare density at the pixel scale $(30 \mathrm{~m}$ grid resolution) for the whole Park, using the number of snare locations $(n=56)$ rather than the number of snare hotspots as the sampling unit. To avoid pseudo-replication we included the number of hotspots as a random factor but found it to be insignificant.
The most parsimonious negative binomial model had a selection probability of 0.986 and explained about two thirds $\left(R^{2}=0.66\right)$ of the variation in snare densities in the Park. Assessment of this model, using bootstrapping techniques, showed that its parameter coefficient estimates were similar to those obtained via the bootstrap crossvalidation (Table 1). The similarity of the two models implies that the same model would be identified as the best model if the analysis were repeated under similar conditions, using a different field dataset. Therefore, the model can be used for predicting snare densities in the Park reliably.

The results of the most parsimonious model indicated eight significant drivers of snare density in the Park: burned status of the vegetation, wildlife density, slope, and distances to surface water resources, roads, roan home range, salt licks and the Park boundary (Table 1). High snare densities occurred in burned vegetation, in areas with low wildlife density and far away from roan antelopes and roads, and in areas near water resources and salt licks. The density of snares increased with slope from 9.6 snares per $\mathrm{km}^{2}$ at $0^{\circ}$ up to a maximum of 17.5 snares per $\mathrm{km}^{2}$ at $11^{\circ}$ and then decreased as the slopes became steeper (Fig. 3a). There were no snares on slopes $>25^{\circ}$. The density of snares also increased with distance from the Park boundary up to 17.2 snares per $\mathrm{km}^{2}$ at $1.5 \mathrm{~km}$ and then decreased continuously beyond this threshold (Fig. 3b).

We used the best model of snare distribution to map the risk of snaring and found that $46 \%$ of the Park area has a high snaring risk and $77 \%$ has moderate to high snaring risk (Fig. 4). A roan habitat suitability map prepared by Kimanzi (2011) indicated that $30 \%$ of the suitable habitat for roan antelopes is located in areas of high snaring risk. Furthermore, $96 \%$ of the moderately to highly suitable roan habitat is located in the areas of moderate to high snaring risk.

\section{Discussion}

The clumped snare patterns suggest that poachers have identified sites with high potential for catching their targeted species, based on their experience or indigenous knowledge of the species' behaviour (Gadgil et al., 1993). This implies that if these sites are well documented and mapped the Park's limited security team will be able to combat illegal hunting more effectively by focusing their patrol efforts on these few snare hotspots instead of on the whole Park. If a snare is found in a new area it can be a clue for the security team to search the surrounding area for snares within a radius of $4 \mathrm{~km}$.

Understanding the factors that influence snare distribution is a vital prerequisite for formulating effective anti-poaching interventions. High densities of snares were located in burned areas of vegetation, which suggests that 
TABLE 1 Predictive model results (best and bootstrap) for 10 variables, based on negative binomial regression for the distribution of snares in Ruma National Park, Kenya (Fig. 1).

\begin{tabular}{lcr}
\hline & Best model & Bootstrap model \\
\cline { 2 - 3 } Predictor & Parameter estimate \pm SE & Parameter estimate \pm SE \\
\hline Slopes & $0.26110 \pm 0.02470$ & $0.24801 \pm 0.01089$ \\
Slopes & $-0.00669 \pm 0.00095$ & $-0.00588 \pm 0.00052$ \\
Vegetation burned status & $0.62300 \pm 0.10910$ & $0.60055 \pm 0.02003$ \\
Wildlife density & $-0.01808 \pm 0.00565$ & $-0.01520 \pm 0.00209$ \\
Distance to water & $-0.00124 \pm 0.00012$ & $-0.00101 \pm 0.00009$ \\
Distance to roads & $0.00071 \pm 0.00005$ & $0.00075 \pm 0.00002$ \\
Distance to salt licks & $-0.00095 \pm 0.00005$ & $-0.00079 \pm 0.00002$ \\
Distance to roan home range & $0.00020 \pm 0.00003$ & $0.00018 \pm 0.00001$ \\
Distance to Park boundary & $0.00323 \pm 0.00031$ & $0.00243 \pm 0.00022$ \\
Distance to Park boundary & $-0.00001 \pm 0.00000$ & $-0.00001 \pm 0.0000$ \\
\hline
\end{tabular}

${ }^{*}$ Slopes and Distance to Park boundary showed a curved relationship with snare density, unlike the other variables, which showed a linear relationship.
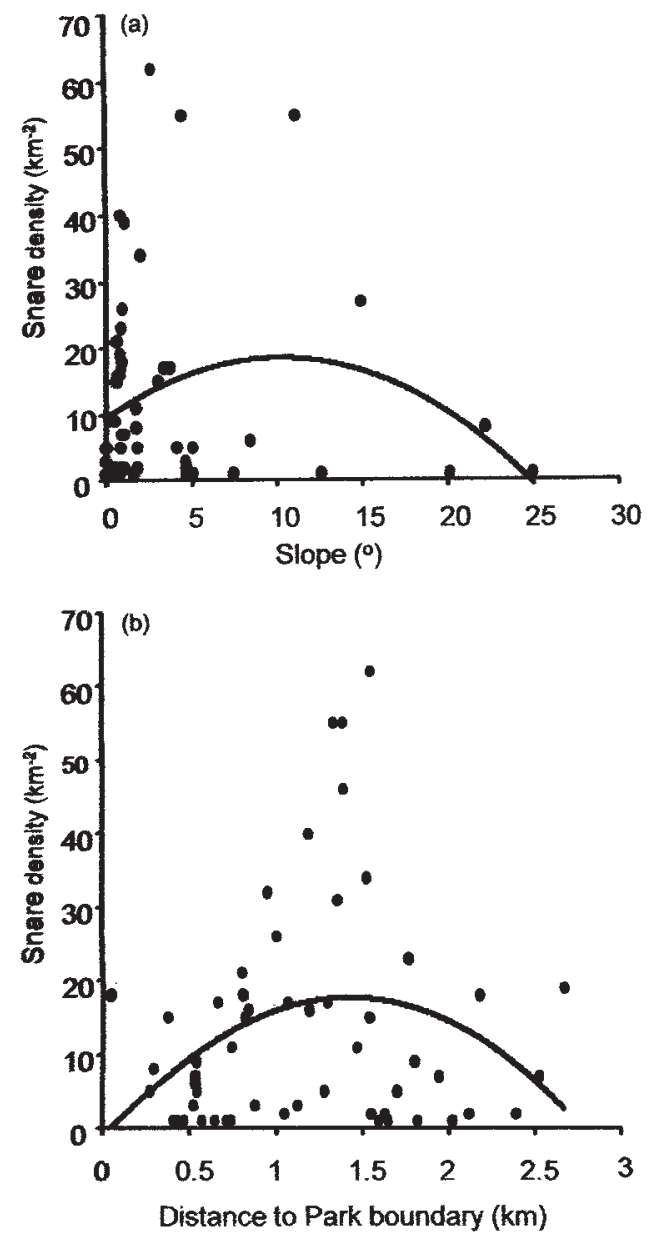

FIG. 3 Relationship between snare density and (a) slope and (b) distance from the Ruma National Park boundary. Points indicate the observed relationship and the line represents the result of the best negative binomial model.

poachers burn the vegetation with the intention of poaching the animals that are attracted by the consequent sprouting of green grass. However, we detected no significant difference in the snare density in grassland and nongrassland habitats (bushland and forested areas), which may indicate that poachers are targeting both grazers and browsers that utilize grasslands and non-grasslands. Wato et al. (2006) made similar findings for Tsavo National Park, which harbours relatively equal proportions of grazers and browsers.

Our results showed that snare density was negatively associated with wildlife density and distance to roan locations, which may be an indicator that animals are deliberately avoiding snared areas. For example, Kimanzi (2008) observed that a particular roan group in the Park behaved in a scared manner near thick vegetation but was calm when encountered in open grasslands. This suggests that roan antelopes are aware of areas with high poaching risk as a result of past experience and may choose to avoid such areas. Joubert (1976) found that roan antelopes avoid thick vegetation in Kruger National Park, South Africa. Similarly, analysis of habitat selection by Kimanzi (2012), using compositional analysis, indicated that roan antelopes avoid habitats near thick vegetation in Ruma National Park. The negative correlation between snare density and wildlife density may also be an indicator that wildlife has been eliminated from areas that have experienced high levels of poaching over a long period. Wire snares can remain functional for up to 2 years (Noss, 1998) and hence the occurrence of high snare density in some parts of the Park may be an indicator that wildlife density was once high in those areas, although it may now be low as a result of hunting.

Although there was a negative correlation between snare density and the occurrence of roan antelopes, mapping of the overall snaring risk in the Park showed that some areas of high risk were located in the roan home range. Population viability analysis of roan antelopes in the Park (Kimanzi, 2012) indicated that the decline in the roan population was mainly a result of poaching and that the population could 


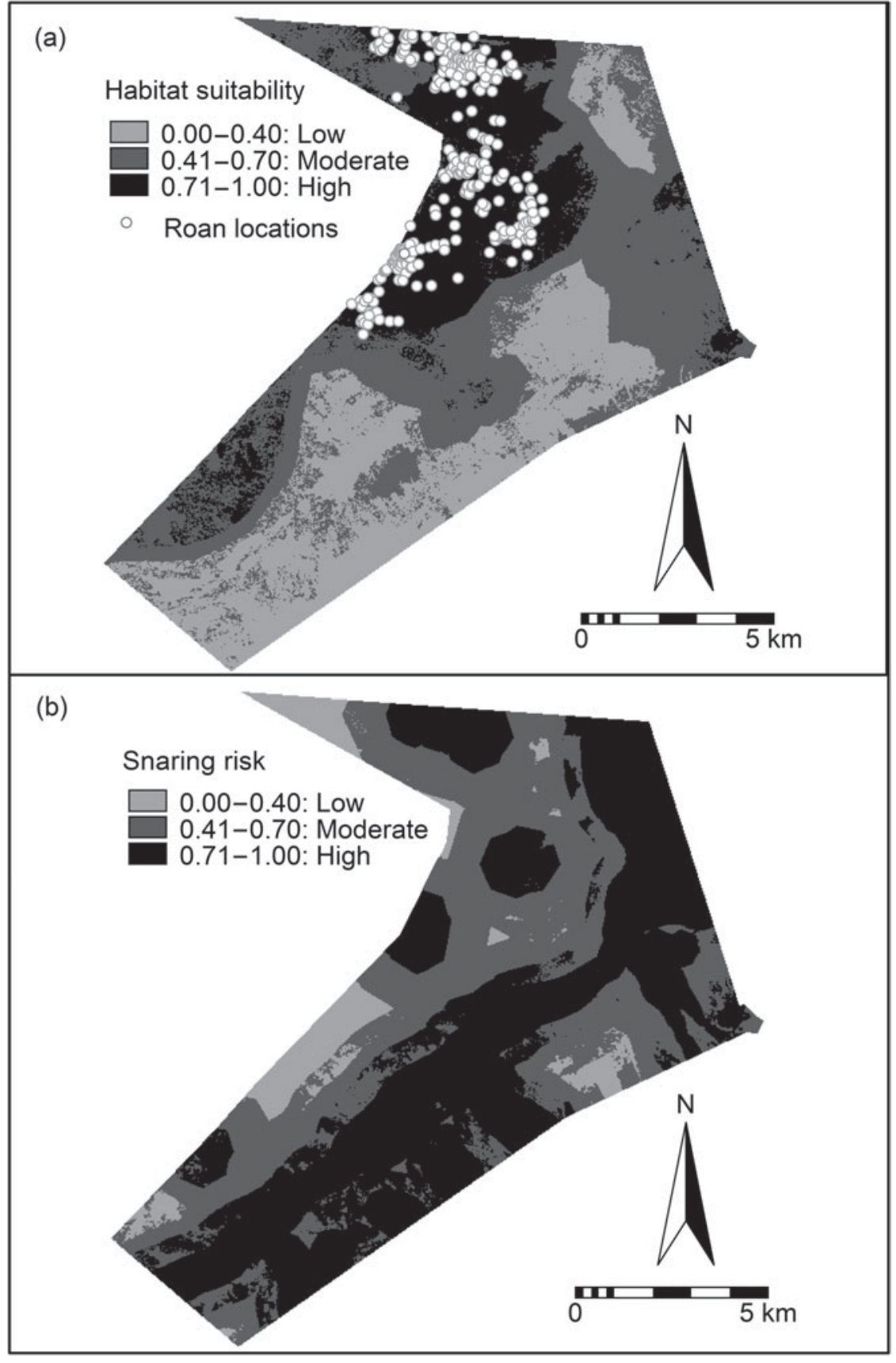

FIG. 4 Habitat suitability (a) and risk of snaring (b) for roan antelope in Ruma National Park. The habitat suitability map was obtained from Kimanzi (2011) and the snaring risk map was derived from negative binomial regression models. not recover to healthy levels unless annual mortality rates attributed to poaching were reduced to $<15 \%$, compared to current losses of $21 \%$ (Kimanzi, 2012). Although the roan antelope may not be the main species targeted by hunters it appears to be the worst affected by poaching because of the small population. Edroma \& Kenyi (1985) found that some species in small protected areas in East Africa were potentially at risk of local extinction from illegal hunting. In North America overhunting is the leading cause of endangerment and extinction among mammals (Hayes, 1991). The problem of poaching needs to be resolved to ensure sustainable conservation of the threatened roan antelope in Ruma National Park.
Other significant factors influencing the distribution of snares included slope and the distances to water, roads, salt licks and the Park boundary. The highest numbers of snares were mainly found in areas with slopes of $0-20^{\circ}$, which appears to be the optimum range for most species of grazing animals. Kimanzi (2011) showed that the roan antelope prefers areas with slopes of $0-10^{\circ}$. Some parts of the Park have steep slopes that are inaccessible to many grazers.

Snare hotspots occurred near essential resources such as water and salt licks, which animals visit frequently. Therefore, concentrating routine security patrols on areas near water sources and salt licks rather than patrolling 
the whole Park could be more effective for curbing illegal hunting.

Although roads can facilitate access by hunters to snare sites, most snares were far from the roads, probably to avoid being seen by rangers on routine security patrols. This means that vehicle-based security patrols by road will not be effective unless complemented by intensive foot patrols. A study by Arcese et al. (1995) confirmed that a combination of vehicle and foot patrols is more effective in combating bushmeat hunting than either by vehicle or foot patrol alone.

The last factor influencing snare distribution was the distance from the Park boundary; snare density increased up to $1.5 \mathrm{~km}$ and then decreased with increasing distance. This supports the findings of Wato et al. (2006), who found that trap abundance increased with distance from the Park boundary and peaked at $4 \mathrm{~km}$, then decreased rapidly. This trend in snare abundance is consistent with the behaviour of local bushmeat hunters in Africa. Snares must be checked frequently to ensure that ensnared animals do not break free and escape or are not eaten by other predators or lost to decomposition (Wato et al., 2006). Noss (1998) estimated that a quarter of snared wild animals are lost to decomposition or scavenging, which makes trapping a wasteful and destructive method of utilizing wildlife. Furthermore, poachers need to carry snares and their catch, which makes it impractical for them to travel far from their homes to set the traps (Fitzgibbon et al., 1995). Therefore, maintaining a fully functional fence around the Park boundary can reduce access by poachers. About onequarter of the Park is unfenced and in other areas the fence has been vandalized to supply wire for snares.

In summary, snares in Ruma National Park occur in clumps (hotspots) up to $4 \mathrm{~km}$ apart. These hotspots occur (1) near water resources, salt licks and the Park boundary, (2) far from locations of roan antelopes and roads, (3) in areas with low slopes and low wildlife density, and (4) in areas with burned vegetation. Therefore, for effective control of bushmeat hunting in the Park, law enforcement efforts need to be concentrated around these hotspots.

Apart from increasing the frequency of security patrols around snare hotspots, security could be improved by the construction of a road around the Park boundary to facilitate movement of the security team. Improved roads can also increase the frequency of tourist vehicles throughout the year and thus reduce poaching.

We presented our research at a workshop organized by Kenya Wildlife Service for national roan antelope conservation strategy stakeholders in September 2011. Our findings are being used by the national roan antelope conservation task force to develop a conservation strategy for sustainable conservation of roans in Kenya. Meanwhile, security in Ruma National Park has improved following the translocation of 20 black rhinoceros Diceros bicornis from Mugie Rhino Sanctuary and Solio Ranch in January 2012 (The Star, 2013).

\section{Acknowledgements}

We thank the Commonwealth Scholarship Commission for funding this research, the Kenya Wildlife Service for granting permission to conduct research in Ruma National Park, and the Regional Centre for Mapping of Resources for Development and the Ruma National Park authorities for providing secondary data.

\section{References}

African Pro-poor Tourism Development Centre (2013) Making Tourism Work for the Poor in Africa. Http://www. propoortourism-kenya.org/success_stories.htm [accessed 5 March 2013].

Allsopp, R. (1979) Roan antelope population in the Lambwe Valley, Kenya. Journal of Applied Ecology, 16, 109-115.

Alpers, D.L., Van Vuuren, B.J., Arctander, P. \& Robinson, T.J. (2004) Population genetics of the roan antelope (Hippotragus equinus) with suggestions for conservation. Molecular Ecology, $13,1771-1784$.

Ansell, W.F.H. (1971) Family Artiodactyla. In The Mammals of Africa: An Identification Manual Part 2 (eds J. Meester \& H.W. Setzer), pp. 15-83. Smithsonian Institution Press, Washington, DC, USA.

Arcese, P., Hando, J. \& Campbell, K. (1995) Historical and present-day anti-poaching efforts. In Serengeti II: Dynamics, Management, and Conservation of an Ecosystem (eds A.R.E. Sinclair \& P. Arcese), pp. 95-107. The University of Chicago Press, Chicago, USA.

Baddeley, A. \& Turner, R. (2005) spatstat: An R package for analyzing spatial point patterns. Journal of Statistical Software, $12,1-42$.

Barnett, R.F. (1997) Food for Thought: the Utilization of Wild Meat in Eastern and Southern Africa. TRAFFIC, Nairobi, Kenya.

Bolker, B.M., Brooks, M.E., Clark, C.J., Geange, S.W., Poulsen, J.R., Stevens, M.H.H. \& White, J.S.S. (2009) Generalized linear mixed models: a practical guide for ecology and evolution. Trends in Ecology \& Evolution, 24, 127-135.

Carter, N. (1989) Preserving the pachyderm. Africa Report, $34,45-48$.

Crawley, M.J. (2007) The R Book. John Wiley \& Sons, Chichester, UK

Edroma, E.L. \& KenYi, J.M. (1985) Drastic decline in bohor reedbuck (Redunca redunca Pallas 1977) in Queen Elizabeth National Park, Uganda. African Journal of Ecology, 23, 53-55.

FA, J.E., RYAN, S.F. \& BELL, D.J. (2005) Hunting vulnerability, ecological characteristics and harvest rates of bushmeat species in afrotropical forests. Biological Conservation, 121, 167-176.

Fitzgibion, C.D., Hezron, M. \& Fanshawe, J.H. (1995) Subsistence hunting in Arabuko-Sokoke Forest, Kenya, and its effects on mammal populations. Conservation Biology, 9, 1116-1126.

Gadgil, M., Berkes, F. \& Folke, C. (1993) Indigenous knowledge for biodiversity conservation. Ambio, 22, 151-156.

HAYES, J.P. (1991) How mammals become endangered. Wildlife Society Bulletin, 19, 210-215. 
ILWIS (Integrated Land and Water Information System) (2009) ILWIS Open Software v. 3.6. Http://52north.org/downloads/ ilwis [accessed 23 August 2009].

IUCN (2008) Hippotragus equinus. In IUCN Red List of Threatened Species v. 2013.2. Http://www.iucnredlist.org [accessed 31 March 2014].

Jouber T, S.C.J. (1976) The population ecology of the roan antelope, Hippotragus equinus equinus (Desmarest, 1804), in the Kruger National Park. DSc thesis. University of Pretoria, Pretoria, South Africa.

KImANZI, J.K. (2008) The declining endangered roan antelope population in Kenya: what is the way forward? In 18th Eastern Africa Environmental Network (EAEN) Conference Proceedings. Nairobi, Kenya.

KimANZI, J.K. (2011) Mapping and modelling the population and habitat of the roan antelope (Hippotragus equinus langheldi) in Ruma National Park, Kenya. PhD thesis. Newcastle University, Newcastle upon Tyne, UK.

Kimanzi, J.K. (2012) Roan Antelope Population and Habitat Evaluation in Ruma National Park: Implications for Management. Lambert Academic Publishing, Saarbrucken, Germany.

Kones, D. (2005) The Status of Kenya's Roan Antelope (Hippotragus equinus langheldi) in Ruma National Park 1974-2005. Kenya Wildlife Service, Nairobi, Kenya.

KWS (Kenya Wildlife Service) (1990) A Policy Framework and Development Programme 1991-1996. Kenya Wildlife Service, Nairobi, Kenya.

KWS (Kenya Wildlife Service) (2006) Ruma National Park: Official Guidebook. Kenya Wildlife Service, Nairobi, Kenya.

Manly, B.F.J. (2007) Randomization, Bootstrap and Monte-Carlo Methods in Biology. 3rd edition. Chapman \& Hall, London, UK.

Montgomery, D.C. \& Peck, E.A. (1992) Introduction to Linear Regression Analysis. Wiley, New York, USA.

Noss, A.J. (1998) The impacts of cable snare hunting on wildlife populations in the forests of the Central African Republic. Conservation Biology, 12, 390-398.

Омото, W.O. (1994) The soil resources of Ruma National Park in Lambwe Valley, Kenya. MSc thesis. University of Nairobi, Nairobi, Kenya.
Oтtichilo, W. (1995) Revised Draft Kenya Wildlife Management Policy. Results of a workshop held at IUCN Eastern Africa Regional Office, Nairobi, Kenya.

R Development Core Team (2010) R: A Language and Environment for Statistical Computing. R Foundation for Statistical Computing, Vienna, Austria. Http://www.r-project.org [accessed 20 September 2010].

Ripley, B.D. (1976) The second-order analysis of stationary point processes. Journal of Applied Probability, 13, 255-266.

The Star (2013) 20 rhinos for Ruma to boost Western tourism. Http://www.the-star.co.ke/news/article-31624/20-rhinos-rumaboost-western-tourism [accessed 4 April 2013].

Venables, W.N. \& Ripley, B.D. (2002) Modern Applied Statistics with $S$. 4th edition. Springer, New York, USA.

Wato, Y.A., Wahungu, G.M. \& OKello, M.M. (2006) Correlates of wildlife snaring patterns in Tsavo West National Park, Kenya. Biological Conservation, 132, 500-509.

Waweru, F.K., Alina, C. \& Musyoki, C.M. (1995) Rhino Habitat Suitability Assessment in Ruma National Park. Kenya Wildlife Service, Nairobi, Kenya.

Zuur, A.F., Ieno, E.N. \& Elphick, C.S. (2010) A protocol for data exploration to avoid common statistical problems. Methods in Ecology and Evolution, 1, 3-14.

Zuur, A.F., Ieno, E.N. \& Smith, G.M. (2007) Analysing Ecological Data. Springer Science + Business Media, New York, USA.

\section{Biographical sketches}

Johnstone Kimanzi is interested in applying GIS and remotesensing tools to solve biodiversity conservation and wildlife management problems. ROY SANDERSON is interested in modelling complex ecological systems across a wide range of spatio-temporal scales. STEPHEN RUSHTON is interested in analysing the structure and dynamics of complex biological and clinical systems to develop approaches for investigating spatially and temporally heterogeneous processes. Mware Mugo has worked as a forest ecologist in Kenya for over 15 years. 